\title{
La dicotomía entre política y derecho y la designación de los jueces en Chile
}

\author{
Alexander Espinoza Rausseo* \\ Jhenny Rivas Alberti**
}

\begin{abstract}
RESUMEN
En el presente trabajo analizaremos la independencia externa de los jueces, a la luz del principio de independencia e imparcialidad del juez, tomando en consideración las normas expresas de la Constitución Política, interpretadas a la luz de los objetivos perseguidos por el principio de separación de poderes, especialmente en el sentido desarrollado por las normas internacionales de derechos humanos. Asimismo, se plantea la posibilidad de realizar un análisis de convencionalidad, las que podrían ser revisadas en su conformidad con los estándares internacionales, normas de cualquier jerarquía, incluso normas de la propia Constitución. Especialmente productivo puede resultar la aplicación del estándar internacional de derechos bumanos, para la interpretación conforme y más favorable a los derechos fundamentales de las normas aplicables.
\end{abstract}

Separación de poderes; independencia judicial; selección de los jueces

\section{The political-right dichotomy and the Designation of judges in Chile}

\begin{abstract}
In the present work we will analyze the external independence of the judges, in the light of the principle of independence and impartiality of the judge, taking into account the express norms of the Political Constitution, interpreted in the light of the objectives pursued by the principle of separation of powers, especially in the sense developed by international human rights standards. On the other hand, the possibility of carrying out an analysis of conventionality is raised, through which they could be reviewed in accordance with international standards, norms of any
\end{abstract}

* Abogado por la Universidad Santa María, Caracas, Venezuela. Doctor en Derecho, Universität Passau, Alemania. Director General del Instituto de Estudios Constitucionales, sede Chile. ORCID: http://orcid. org/0000-0001-7600-3054 .Correo electrónico: espinoza@estudiosconstitucionales.com

** Abogado por la Universidad Central de Venezuela. Doctora en Derecho, Universidad de Zaragoza, España. Académica Investigadora, Facultad de Ciencias Sociales y Económicas, Departamento de Ciencias Sociales, Universidad Católica del Maule, Chile. ORCID:http://www.orcid.org/0000-0002-2589-6742. Correo electrónico: jhenny.rivas@estudiosconstitucionales.com.

Artículo recibido el 26.2.20 y aceptado para su publicación el 15.6.20. 
bierarchy, including norms of the Constitution itself. Especially productive, the application of the international standard of human rights, for the conforming interpretation and more favorable to the fundamental rights, of the applicable norms may result.

Separation of powers; judicial independence; Selection of the judges.

\section{INTRODUCCIÓN}

$\mathrm{D}$ e acuerdo con la doctrina dominante en Chile, nuestro sistema judicial se ubica comparativamente más dirigido por las fuerzas internas de la burocracia judicial y no como un sistema en que la clase política ejerce gran influencia en el proceso de selección de los jueces ${ }^{1}$. A pesar de esta valoración positiva, nos proponemos poner en cuestionamiento la vigente interpretación y aplicación de las normas acerca del nombramiento de los jueces y sostendremos la tesis de la absoluta incompatibilidad entre los intereses políticos expresados en el nombramiento y el deber de ejercer sus funciones en estricta sujeción a la ley y el derecho.

En Chile, a pesar de la falta de una disposición expresa, el principio de independencia judicial deriva de su reconocimiento como principio jurídico objetivo en el artículo 76, inciso primero de la Constitución Política, y como derecho subjetivo, mediante la garantía de las partes intervinientes ${ }^{2}$ de un procedimiento y una investigación racionales y justos que aseguren el derecho al debido proceso, reconocida en el artículo $19 \mathrm{~N}^{\circ} 3$ inciso $6^{\circ}$. Finalmente, el derecho subjetivo a la admisión a todas las funciones y empleos públicos se encuentra establecido en el artículo $19 \mathrm{~N}^{\circ} 17$. Esta disposición exige que la admisión a las funciones y empleos públicos no sea discriminatoria ${ }^{3}$. Por su parte, la Convención Americana sobre Derechos Humanos o Pacto de San José dispone en su artículo 8.1 que "[t]oda persona tiene derecho a ser oída[...] por un juez o tribunal [...] independiente”. La redacción es similar a la del artículo 10 de la Declaración Universal de los Derechos Humanos, según esta, "[t]oda persona tiene derecho[...] a ser oída públicamente y con justicia por un tribunal independiente e imparcial [...]. Ambas disposiciones han dado lugar a un abundante desarrollo interpretativo por parte de organismos internacionales.

Nuestra pregunta de investigación está entonces referida a determinar ¿cuál es el papel que juega el principio de independencia de los jueces en la interpretación del

${ }^{1}$ SÁEz, 2005; Mesa interinstitucional, 2019, p. 8; MacClure, 2018, p. 4. En cuanto a la evolución del sistema judicial desde el gobierno militar en Chile, SKaAr, 2003; VArgas, 2018, p. 113; Correa, 2005, p. 123. En cuanto a la evolución histórica de la judicatura en América Latina, SÁEZ, 2005. En cuanto a las propuestas de reforma constitucional en Chile, VARGAS, 2018, p. 123.

2 TC Rol No 1243 de 30-12-2008, 18 ; TC Rol No 2180 de 17 de mayo de 2012, $27^{\circ}$.

${ }^{3}$ Corte Suprema, Sala Cuarta (Mixta). Causa N 28429/2016 (Unificación de Jurisprudencia). Resolución No 89191 de 7 de marzo de 2017; Corte Suprema, Sala Cuarta (Mixta). Causa No 28427/2016 (Unificación de Jurisprudencia). Resolución No 89166 de 7 de marzo de 2017; Corte Suprema, Sala Cuarta (Mixta). Causa No 1482/2018 (Unificación de Jurisprudencia). Resolución No 6 de 3 de abril de 2018. 
contenido de disposiciones orgánicas de la propia Constitución Política? Con estos fines analizaremos la independencia externa de los jueces, tomando en consideración las normas expresas de la Constitución Política, interpretadas a la luz de los objetivos perseguidos por el principio de separación de poderes, especialmente en el sentido desarrollado por las normas internacionales de derechos humanos, pero también acudiremos al análisis de normas y jurisprudencia comparada, sobre todo, de Alemania y España. Estudiaremos la influencia del principio de independencia e imparcialidad del juez en el diseño e interpretación de las normas que regulan la competencia de los órganos que intervienen en la designación de los jueces, así como el procedimiento aplicable y el ámbito de discrecionalidad del órgano competente. Revisaremos algunos aspectos relevantes en el sistema de nombramientos de los jueces, a base de los criterios de idoneidad y de independencia política, con especial referencia a la selección de los ministros de la Corte Suprema, así como de otros jueces y funcionarios judiciales.

\section{LA JUSTIFICACión MATERIAL DE LA INDEPENDENCIA DE LOS JUECES}

El principio de independencia se considera inherente a la función jurisdiccional ${ }^{4}$. Su justificación material deriva del principio de separación de los poderes públicos ${ }^{5}$, en el sentido de la resistencia de los jueces frente a los poderes legislativo y ejecutivo ${ }^{6}$, de forma tal que constituye una garantía de protección de los derechos y libertades individuales ${ }^{7}$. El principio estructural de separación de poderes ostenta entonces un contenido axiológico específico, por lo que atañe al presente estudio, mediante la garantía de independencia judicial.

En la doctrina alemana, si bien se alude a una concordancia práctica entre la sujeción al principio de idoneidad, capacidad y méritos del art. 33 aparte 2 de la Ley Fundamental y la función de los ministros y comisiones judiciales de selección, de dotarlos de una elevada legitimación democrática ${ }^{8}$, sin embargo, en la práctica judicial se ha establecido que el principio de igualdad de acceso a los cargos públicos, de acuerdo con su idoneidad, capacidad y méritos, consagrado en el art. 33 aparte 2 de la Ley Fundamental, tiene

${ }^{4}$ TC Rol No 46-87, de 21-12-1987, $10^{\circ}$; TC Rol No 1243 de 30-12-2008, $12^{\circ}$; Comité de Derechos Humanos, 2014, párr. 32. En cuanto al valor de las recomendaciones en el derecho nacional chileno, TC Rol N³016-16 de 9 de mayo de 2016; Delaveau et al., 2017, p. 20; Corte IDH Caso Caballero Delgado y Santana, Sentencia de 8 de diciembre de 1995, párr. 67.

${ }^{5}$ Corte IDH Tribunal Constitucional Vs. Perú, Sentencia de 31 de enero de 2001; Chocrón Chocrón Vs. Venezuela, Sentencia de 1 de julio de 2011, párr. 97. La separación entre el poder judicial y los poderes de gobierno es el caso más típico e importante de la separación de funciones, según Ferrajoli, 2013a, p. 829.

${ }^{6}$ Fuentes, 2016, p. 204; Ferrajoli, 2006, p. 97; Melgarejo, 2019, p. 597.

${ }^{7}$ Relatora Especial sobre la cuestión de Defensores de la ONU. Folleto No. 29; Comisión Interamericana de Derechos Humanos, 2013, párr. 78; Ferrajoli, 2006, p. 96; Jellinek, 1921, p. 615; Fuentes, 2011, p. 48; Lucas, 2009, p. 243.

${ }^{8}$ Wittreck, 2006, p. 421; Umbach \& Dollinger, 2007, p. 50. 
vigencia sin limitaciones o reservas ${ }^{9}$. No son admisibles limitaciones que relativicen la importancia del principio de mérito ${ }^{10}$. Solo podrían ser tomados en consideración otros intereses distintos del principio de mérito para el nombramiento en cargos públicos, en caso de encontrarse previstos constitucionalmente y hubieran sido objeto de ponderación, por medio de una disposición legislativa ${ }^{11}$. Toda solicitud de ingreso debe ser evaluada conforme a los mencionados criterios $^{12}$.

La doctrina dominante rechaza la necesidad de dotar a los jueces de un mayor grado de legitimidad política directa. En criterio de Brewer-Carías, el punto de vista del origen democrático de la elección de los jueces es contrario a la esencia de la función judicial, es decir, que los jueces deben ser independientes de las otras ramas del poder público; y en la decisión de los casos deben estar exentos de presiones, de manera de poder decidir los casos solo sometidos a la ley ${ }^{13}$. Por el contrario, se afirma la legitimidad del juez, a partir del hecho de que decide con sujeción a la ley ${ }^{14}$, entre otras teorías ${ }^{15}$. En principio, la legitimación democrática no solo se transfiere por elección popular, sino que resulta suficiente una legitimación indirecta, mediante una cadena ininterrumpida, hasta los órganos dotados de funciones públicas ${ }^{16}$.

Según Ferrajoli, la separación entre poder legislativo y poder ejecutivo de un lado y poder judicial de otro, deriva de su distinta fuente de legitimación, la que consiste, para los dos primeros en la representación política en función de intereses generales, para el tercero de la rígida sujeción a la ley con su aplicación también sustancial ${ }^{17}$. En nuestro criterio, la teoría expuesta por Ferrajoli puede ser complementada con la

${ }^{9}$ BVerwG 2 VR 1.16, Beschluss vom 21. Dezember 2016, Abs. 21; BVerwG 2 C 23.03, Urteil vom 28. Oktober 2004.

${ }^{10}$ VG Karlsruhe, Beschluss vom 17.01.2013 - 1 K 2614/12. Abs. 9; BVerwG 2 C 23.03, Urteil vom 28. Oktober 2004.

${ }^{11}$ BVerwG 2 C 23.03, Urteil vom 28. Oktober 2004. El Tribunal Federal Constitucional de Alemania ha establecido que, si bien los jueces de los tribunales superiores de la Federación no están excluidos del alcance del artículo 33.2 de la Ley Fundamental (párr. 21), sin embargo el art. 95 aparte 2, impone modificaciones frente a la designación puramente ejecutiva (párr. 16). BVerfG, Beschluss des Zweiten Senats vom 20. September 2016 - 2 BvR 2453/15 -, Rn. (18). Una postura contraria ha sido sostenida respecto de los jueces de los Länder, en cuya designación rigen sin limitaciones los principios de idoneidad, capacidad y méritos. OVG Schleswig-Holstein, 21.10.2019 - 2 MB 3/19.

12 BAG 6 de mayo de 2014 Exp. 9 AZR 724/12, párr. 15

13 Brewer-Carías, 2005, p. 2. Un criterio distinto es sostenido por Popkin, 2002, p. 51; VARGas, 2014, p. 143.

${ }^{14}$ Ferrajoli, 2013a, p. 828 y Ferrajoli, 2013b, p. 75; 208; Posner, 2011, p. 156; Atria, 2007, p. 41; Bordalí, 2009b, p. 221; Harbottle, 2019, p. 33; Galindo, 1990, p. 166; Lopera, 2001, p. 250; Muller \& Clovis, 2016, p. 228; Correa, 2005, p. 123; López, 2018, p. 3. Crítico de este argumento, LÓPEZ, 1997, p. 62; GAVIRIA, 2019.

15 Por ejemplo, la legitimación a partir de los procesos deliberativos. VAN HoEcke, 2012, p. 20; Durango, 2007, 200.

${ }^{16}$ En este sentido, el Tribunal Constitucional Federal de Alemania en, BVerfGE 83, 60 - Ausländerwahlrecht II; Correa, 2005, p. 121; López, 1997, p. 74.

${ }^{17}$ Ferrajoli, $2013 \mathrm{a}$, p. 824; 827. 
distinción entre intereses generales e intereses individuales jurídicamente protegidos, esto es, derechos subjetivos.

La función jurisdiccional tiene por objeto la constatación y sanción o reparación de la lesión de un derecho subjetivo ${ }^{18}$, por lo que su ámbito de acción de la función jurisdiccional no está puesto en los intereses generales, sino en los derechos subjetivos, intereses legítimos y posiciones jurídicas que manifiestan los litigantes en el proceso ${ }^{19}$, mientras que el ámbito natural donde actúa la administración es el de los intereses generales ${ }^{20}$.

En este ámbito, de claro predominio de intereses individuales, la organización y los procedimientos deben estar regidos exclusivamente por la garantía individual de que la controversia sea resuelta por un órgano independiente e imparcial. Similares consideraciones son aplicables en el caso de la delimitación entre sanciones penales ${ }^{21}$ y administrativas. Las garantías del debido proceso y de independencia e imparcialidad son aplicables proporcionalmente a la gravedad de la limitación que derivan de la prohibición y la sanción penales. De allí derivan las reservas en favor del juez penal, como por ejemplo en el caso de las penas privativas de libertad ${ }^{22}$.

En lo que atañe al principio de independencia judicial, podemos concluir que toda dependencia o condicionamiento de tipo mayoritario de las funciones de garantía equivale a una indebida interferencia ${ }^{23}$. La aplicación del principio democrático a la estructura judicial resultaría contraria a la esencia de la función judicial ${ }^{24}$ y no es una justificación suficiente para reducir el margen de autonomía de los jueces ${ }^{25}$.

${ }^{18}$ Ferrajoli et all, 2001, p. 26; GonZÁlez, 2014, p. 130; Alcalá-Zamora y Castillo, 1992, p. 51; Bordalí, 2013; Bordalí, 2007, p. 7. Ramos, 1984, p. 424; TC Rol No 1448-09 de 7 de septiembre de 2010, 13º; Gordillo, 2017, p. IX-12; DAmašKa, 2000, p. 155; FuENZALIdA y VAlderrama, 2017, p. 189. Véase también una relación detallada de las teorías subjetivas y objetivas de la función jurisdiccional en, Pérez-Cruz, 2015; Nieva, 2017, p. 107.

${ }^{19}$ Moraga, 2011, pp. 235, 237; Bordalí, 2013; Bordalí, 2009a.

${ }^{20}$ Ferrajoli, 2005, p. 88; GonZÁlez, 2014, p. 130; Moraga, 2011, p. 235.

${ }^{21}$ En su concepción inicial, el derecho penal se encontraba orientado a la protección de la libertad individual. Para Savigny la pena era una garantía de protección frente a violaciones de los derechos subjetivos (Von Savigny, 1879, p. 7.); para Kant su finalidad era la protección del libre desenvolvimiento de la personalidad del individuo. Mientras que Feuerbach mantuvo esta posición, se atribuye a Birnbaum, Binding y Von Lisz el tránsito del derecho subjetivo de la víctima al bien jurídico protegido como interés general (Eser, 1996, p. 1010).

22 TC Rol No 1518-09 de 21 de octubre de 2009, 5; TC Rol N 2381-12 de 20 de agosto de 2013,

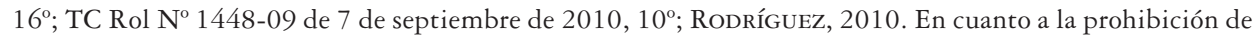
autoincriminación en procedimientos jurisdiccionales no criminales o a actuaciones administrativas, véase también TC Rol No 2897-15 de 4 de julio de 2017, $19^{\circ}$.

${ }^{23}$ Ferrajoli, 2013a, p. 829.

${ }^{24}$ Brewer-Carías, 2005, p. 2. En el derecho comparado, Loewenstein destaca que ni designación de los jueces ingleses, ni el ejercicio de su cargo, se encuentran influenciados en modo alguno por motivos políticos (LOEWENSTEIN, 1967, p. 67), a diferencia del caso norteamericano, en el que se reconoce que la nominación que corresponde al Presidente puede encontrarse influenciada por motivos partidistas. Sin embargo, el juez no es apreciado por la población como un funcionario con influencia política. Loewenstein, 1959, pp. $411 ; 413$.

25 Consejo Consultivo de Jueces Europeos (CCJE), 2001, párr. 33; Brewer-Carías, 2005, p. 2; Comité de Derechos Humanos, Informe A/50/40, de 3 de octubre de 1995, párr. 288 y 301. 


\section{CONTENIDO DEL PRINCIPIO DE INDEPENDENCIA}

El objetivo de la independencia del Poder Judicial radica en evitar que el sistema judicial en general y sus integrantes en particular se vean sometidos a posibles restricciones indebidas en el ejercicio de su función por parte de órganos ajenos al Poder Judicial o incluso por parte de aquellos magistrados que ejercen funciones de revisión o apelación ${ }^{26}$. La independencia implica la existencia de un órgano que imparte jurisdicción, pero que está ajeno a presiones concretas. De esta forma, se entiende por independencia la imposibilidad jurídica de dirigir instrucciones o recomendaciones a los miembros de un órgano judicial (u otro órgano que ejerza jurisdicción) en relación con su actividad jurisdiccional ${ }^{27}$. Desde el punto de vista de las normas de organización, el principio de independencia funcional impide la configuración de relaciones de sujeción jerárquica o funcional entre funcionarios que ejercen tareas judiciales, especialmente cuando se refieren al mismo asunto ${ }^{28}$. De este modo la independencia judicial garantiza su carácter tendencialmente cognoscitivo ${ }^{29}$, en donde la validez de una sentencia solo depende de que se encuentre fundada en una correcta comprobación de sus presupuestos de hecho y de derecho.

En cuanto a su contenido específico, la Corte Interamericana de Derechos Humanos ha remitido a la jurisprudencia del Tribunal Europeo de Derechos Humanos ${ }^{30}$, en el sentido que la independencia de cualquier juez supone que se cuente con un adecuado proceso de nombramiento, con una duración establecida en el cargo y con una garantía contra presiones externas ${ }^{31}$. El TEDH ha establecido algunos criterios, como el modo de designación del juez o tribunal, la duración del mandato de los miembros del tribunal, la existencia de una protección contra las presiones externas y la apariencia de independencia ${ }^{32}$.

El TEDH ha señalado que el elemento de independencia se encuentra especialmente referida a la independencia en particular del poder ejecutivo ${ }^{33}$. Para considerar a un órgano como un tribunal "independiente" - en especial, en relación con el poder ejecutivo y con las partes-, hay que tener en cuenta el procedimiento de designación de sus miembros y la duración de sus funciones, la existencia de una normativa de su revocación o de garantías de su inmovilidad, la de una legislación que prohíba al citado

\footnotetext{
${ }^{26}$ Corte IDH Caso Chocrón Chocrón vs. Venezuela Sentencia de 1 de julio de 2011, párr. 97.

${ }^{27}$ CATAlà, 2017, p. 86; STEDH 9273/81 Caso Ettl y otros de 23 de abril de 1987, párr. 38; García, 2011 , p. 60.

${ }^{28}$ En tales términos, la Corte Constitucional de Colombia, en sentencias C-1143/00. y C-436/13.

29 Ferrajoli, 2006, p. 97.

30 También ha remitido a los Principios Básicos de las Naciones Unidas Relativos a la Independencia de la Judicatura, de 1985; a la Observación General 32 del Comité de Derechos Humanos y a los Principios Básicos sobre la Función de los Abogados. Véase las referencias en Delaveau et al., 2017, p. 21

31 Corte IDH Caso del Tribunal Constitucional vs. Perú. Sentencia de 31 de enero de 2001, párr. 75.

32 Moreno, 2018.

33 CATAlà, 2017, p. 86; STEDH 10328/83 Caso Belilos c. Suiza de 29 de abril de 1988, párr. 64
} 
poder darles instrucciones en el ámbito de su competencia contenciosa, la de garantías legales contra las presiones exteriores, las apariencias de independencia y la participación de miembros de la carrera judicial en los procesos $^{34}$.

\section{EL INGRESO DE LOS JUECES}

De acuerdo con el Principio 10 de los Principios Básicos de las Naciones Unidas Relativos a la Independencia de la Judicatura, todo método utilizado para la selección de personal judicial debe garantizar que este no sea nombrado por motivos indebidos. Las personas seleccionadas para ocupar cargos judiciales serán personas íntegras e idóneas y tendrán la formación o las calificaciones jurídicas apropiadas. En la selección de los jueces no se hará discriminación alguna por motivo de raza, color, sexo, religión, opinión política o de otra índole, origen nacional o social, posición económica, nacimiento o condición.

La Corte Interamericana de Derechos Humanos ha señalado que un adecuado proceso de nombramiento y selección constituye un presupuesto esencial para garantizar la independencia de las y los operadores de justicia ${ }^{35}$. En términos similares, la Recomendación N. ${ }^{\circ}$ R (94) del Consejo de Europa advierte que, "toda decisión relativa a la carrera profesional de los jueces debería apoyarse en criterios objetivos, y la selección y la carrera de los jueces deberían fundarse en el mérito, conseguido según sus calificaciones, su integridad, competencia y eficacia”. De allí deriva que, en general, el nombramiento debe hacerse "en función del mérito" y "en base a criterios objetivos" y que las consideraciones políticas deberían ser inadmisibles ${ }^{36}$. Estas reglas objetivas no solo tendrían el fin de excluir cualquier influencia política, sino también por otros motivos, como la preocupación de prevenir el riesgo de favoritismos, conservadurismo y clientelismo, que existe cuando los nombramientos no siguen un procedimiento estructurado o se basan en recomendaciones personales ${ }^{37}$.

Respecto de la garantía de un tribunal independiente, el Comité de Derechos Humanos ha recomendado a Bolivia que el nombramiento de los jueces y magistrados se base en su competencia y no en su filiación política ${ }^{38}$. En el caso de Eslovaquia, el Comité recomendó que se adopten medidas específicas que protejan a los jueces de cualquier forma de influencia política por medio de la aprobación de leyes que reglamenten el

34 STEDH Caso Langborger contra Suecia de 22 de junio de 1989, párr. 116.

${ }^{35}$ Corte IDH Caso Palamara Iribarne vs. Chile. Sentencia de 22 de noviembre de 2005, párr. 156; Corte IDH Caso del Tribunal Constitucional vs. Perú Sentencia de 31 de enero de 2001, párr. 73; FuenTES, 2016, p. 211.

36 Consejo Consultivo de Jueces Europeos (CCJE), 2001, párr. 17; International Bar Association, 2010, p. 134.

37 Consejo Consultivo de Jueces Europeos (CCJE), 2001, párr. 24; Mateos, 2019, p. 146; Dazarola, p. 7

38 Comité de Derechos Humanos Volumen I Suplemento No. 40 (A/52/40), p. 224. 
nombramiento, la remuneración, el mandato, la destitución y las medidas disciplinarias relacionados con los miembros de la judicatura ${ }^{39}$.

La Corte IDH ha advertido que, si no se cumplen ciertos parámetros básicos, el régimen de selección y nombramiento podría facilitar un alto grado de discrecionalidad por parte de las autoridades que participan en el proceso, en virtud de ello, las personas escogidas no serían, necesariamente, las más idóneas ${ }^{40}$. Además de lo problemático que podría resultar la discrecionalidad en un sistema de reelección o ratificación, la Comisión Interamericana considera que un operador de justicia que pretenda ser reelegido o ratificado en sus funciones, corre el riesgo de comportarse de tal modo que obtenga el apoyo de la autoridad encargada de tal decisión, o de que su comportamiento se perciba de este modo por los justiciables ${ }^{41}$. El método de selección de los jueces, ante todo, debe precisamente garantizar que los nombrados no deben permanecer agradecidos de quienes los nombren, o simplemente, que los jueces nombrados no deben ser cargados con ningún sentido de gratitud respecto del órgano del Estado que los seleccionó, de manera que cuando llegue el momento puedan decidir con autonomía e independencia en contra de los intereses de tal ente ${ }^{42}$.

Lo anterior nos permite considerar dos criterios para determinar si un sistema de nombramiento es conforme al principio de independencia e imparcialidad de los jueces, a saber, (i) debe garantizar que las personas escogidas sean las más capaces e idóneas y (ii) que resulte a tal punto objetivo, que se encuentre excluida cualquier influencia política, o de otro tipo, de modo que el nombramiento no genere un sentido de gratitud del juez, o que se perciba de este modo por los justiciables.

\section{La intervención de otros poderes}

En Latinoamérica han sido aplicados los más variados diseños de designación de los magistrados de las Cortes Supremas. La clasificación propuesta por Brewer-Carías ${ }^{43}$, emplea como criterio de delimitación el órgano encargado de la designación, distinguiendo los sistemas que tienen su centro en un órgano político, como ocurre en la mayoría de los países de la región, frente a la competencia de órganos autónomos, tal como ocurre con el nombramiento por un Consejo de la Judicatura independiente en Perú o el nombramiento hecho por cooptación por la misma Corte en Colombia y Ecuador.

El Consejo Consultivo de Jueces Europeos (CCJE) ha cuestionado el nombramiento por el ejecutivo o por el legislativo, debido a que pone en riesgo la independencia de los poseedores de dichos poderes ${ }^{44}$. En su lugar ha sugerido como alternativa el método

39 Comité de Derechos Humanos Volumen I Suplemento No. 40 (A/52/40), p. 379.

${ }^{40}$ Corte IDH. Caso Reverón Trujillo vs. Venezuela. Sentencia de 30 de junio de 2009. párr. 74; CIDH, 2013, párr. 56.

${ }^{41}$ CIDH, 2013, párr. 88.

42 Brewer-Carías, 2005, p. 43; García, 2011, p. 60.

43 Brewer-Carías, 2005, pp. 9 y sig. Véase también la clasificación de Loewenstein, 1959, p. 409.

44 También en este sentido, Ferrajoli, 1987, p. 8. 
que consiste en confiar los nombramientos a un órgano independiente ${ }^{45}$. El Tribunal Constitucional español ha precisado que no sería constitucionalmente admisible la distribución de puestos en el Consejo General del Poder Judicial entre los distintos partidos, en proporción a la fuerza parlamentaria de estos en las Cámaras ${ }^{46}$.

Un criterio distinto ha sido sostenido por el Tribunal Europeo de Derechos Humanos, el que ha declarado que el nombramiento por parte del poder ejecutivo no basta para poner en duda la independencia y la imparcialidad de la persona así designada, tanto más cuanto que en numerosos Estados europeos el nombramiento de los jueces depende del Poder Ejecutivo ${ }^{47}$.

En Chile, el Tribunal Constitucional ha declarado que, en principio, no es objetable la participación del Consejo de Alta Dirección Pública ${ }^{48}$ en el procedimiento para designar los jueces y secretarios abogados de los tribunales Tributarios y Aduaneros ${ }^{49}$.

El Presidente de la República es competente para nombrar a los ministros y los fiscales judiciales de la Corte Suprema (art. $78 \mathrm{CP}$ ); a los magistrados y fiscales judiciales de las Cortes de Apelaciones y a los jueces letrados (art. $32 \mathrm{~N}^{\circ} 12 \mathrm{CP}$ ), así como para la designación de los relatores, y de los demás auxiliares de la Administración de Justicia (art. 459 COT). Es claro de lo anterior, el rol predominante del Presidente de la República en la designación, no solo de las máximas autoridades, sino de todos los funcionarios del poder judicial. De allí deriva el riesgo grave de intervención de criterios políticos y de que sea percibido de tal forma por los ciudadanos. Sin embargo, aun cuando sea recomendable la configuración de órganos independientes, que garanticen cierta distancia del centro del poder político, estimamos que es posible lograr una interpretación conforme $e^{50}$ con el principio de independencia judicial por medio de garantías de procedimiento que reduzcan la discrecionalidad política en favor de una mayor transparencia y objetividad.

\section{La influencia en las normas de procedimiento}

En la jurisprudencia alemana, mientras que inicialmente se sostenía la imposibilidad de revisión judicial de las decisiones de nombramiento y ascenso de los jueces, bajo el

45 Consejo Consultivo de Jueces Europeos (CCJE), 2001, párr. 33

${ }^{46}$ STC 108/1986, de 29 de julio Fj. 13; Murillo, 2018b, p. 355, quien considera que la dimensión política del Consejo es inevitable. Crítico de esta decisión, Nieto, 2007, p. 46.

47 STEDH 10328/83 Caso Belilos c. Suiza de 29 de abril de 1988, párr. 66. Un criterio distinto es sostenido por Bordalí, 2009, p. 293; Quirós, 2018, p. 93. En cuanto a la situación en Latinoamérica, USAID/IFES, 2002, p. 9

48 Órgano que forma parte de la Dirección del Servicio Civil (servicio público descentralizado perteneciente a la administración del Estado) y que tiene como principal objetivo prestar asistencia en la toma de decisiones del Presidente, ministros y jefes de servicios para la provisión de altos cargos públicos.

49 TC Rol No 1243 de fecha 30-12-2008, $16^{\circ}$.

${ }^{50}$ Respecto del principio de interpretación conforme a la Constitución, TC Rol N 3729-17 de 28 de agosto de $2017,27^{\circ}$. Véase además el principio de la constitucionalidad condicionada, en la jurisprudencia colombiana. Por todas, C-349/17. 
argumento del carácter electivo de la decisión ${ }^{51}$, en la actualidad los tribunales ejercen el control de si la decisión se encuentra libre de errores de evaluación y juzgamiento. Las decisiones de las comisiones de selección, consideradas generalmente como simples actos internos $^{52}$, sin cualidad de actos administrativos, son objeto de control judicial, en el sentido de si su ámbito de evaluación en la selección fue ejercida libre de errores, de errores de procedimiento o si se basaron en una incorrecta consideración de los antecedentes fácticos ${ }^{53}$.

El aspirante rechazado no puede lograr generalmente (salvo por el poco probable caso de reducción a cero de la discrecionalidad, en el que solo existe una decisión jurídicamente válida) una declaración judicial de que hubiera tenido derecho a ser seleccionado en lugar del aspirante designado. No se trata entonces de una pretensión dirigida a obtener el nombramiento, sino del derecho a obtener una decisión libre de errores, en cuyo caso el tribunal podría ordenar que se realice un nuevo procedimiento de selección, siempre que exista una posibilidad de resultar seleccionado ${ }^{54}$.

Como consecuencia de la especial dependencia del derecho a la igualdad de acceso a los cargos públicos, respecto del procedimiento, deriva de aquel una importante influencia respecto de las normas de procedimiento ${ }^{55}$. Del derecho a la igualdad de acceso a los cargos públicos, en concordancia con la garantía a la tutela judicial efectiva deriva la obligación de dejar constancia escrita de los motivos fundamentales de la decisión de selección ${ }^{56}$. La documentación escrita de tales motivos permitirá al aspirante decidir si acepta la decisión legítima o si recurre a la protección judicial ${ }^{57}$.

De los criterios de idoneidad, capacidad y méritos deriva un derecho constitucional a obtener una decisión oportuna y adecuada a la solicitud de ingreso. La administración pública no puede excluir a un aspirante del proceso de selección, a base de consideraciones subjetivas $^{58}$. El órgano competente está obligado a admitir las postulaciones de jueces y funcionarios y solo puede otorgar el nombramiento de aquellos aspirantes que sean seleccionados, como el más calificado, mediante un concurso de méritos ${ }^{59}$. La administración pública dispone de un ámbito de juzgamiento en la determinación

\footnotetext{
51 WitTRECK, 2006, p. 421

52 SChNEllenBaCH, 2018, p. 313.

53 WitTreck, 2006, p. 421.
}

${ }^{54}$ BVerfG, Beschluss vom 24.09.2002-2 BvR 857/02. https://openjur.de/u/180890.html., Abs. 20; BAG 12 de octubre de 2010 Exp. 9 AZR 518/09, párr. 21; BVerfG, Beschluss des Zweiten Senats vom 16. Dezember 2015. -2 BvR 1958/13-, Rn. 31

${ }^{55}$ BVerfG, Beschluss der 1. Kammer des Zweiten Senats vom 25. November 2015 -2 BvR 1461/15-, Rn. (14); BVerfG, Beschluss des Zweiten Senats vom 20. September 2016 -2 BvR 2453/15-, Rn. (18).

${ }^{56}$ BVerfG 25 de noviembre de 2011 Exp. 2 BvR 2305/11, párr. 20; BVerfG, Beschluss der 1. Kammer des Zweiten Senats vom 25. November 2015 -2 BvR 1461/15-, Rn. (14); BVerfG, Beschluss des Zweiten Senats vom 20. September 2016 -2 BvR 2453/15-, Rn. (18).

${ }^{57}$ BVerfG, Beschluss der 1. Kammer des Zweiten Senats vom 25. November 2015 -2 BvR 1461/15-, Rn. (14); BVerfG, Beschluss des Zweiten Senats vom 20. September 2016 -2 BvR 2453/15-, Rn. (18).

58 BAG 12de septiembre de 2006. Exp. 9 AZR 807/05, párr. 38

59 VG Karlsruhe, Beschluss vom 17.01.2013-1 K 2614/12. 
de los requisitos contenidos en el perfil para la asignación del cargo, con la finalidad de dar cumplimiento al principio de la mejor selección. Tal decisión debe encontrarse justificada en las funciones efectivas del $\operatorname{cargo} 0^{60}$.

Otro ejemplo de interés es el caso de las designaciones judiciales discrecionales en el sistema español. En diversas ocasiones la Sala Tercera del Tribunal Supremo ha anulado acuerdos de nombramientos discrecionales, en general, por falta de motivación ${ }^{61}$. El Tribunal ha establecido parámetros más estrictos en el caso de las designaciones para Magistrados del Tribunal Supremo, ya que en ellas, por ir referidas a la máxima categoría de la carrera judicial, rigen con el mayor nivel de exigencia los principios de mérito y capacidad $^{62}$. El control judicial ha estrechado de manera importante el ámbito de quienes pueden ser elegidos de este modo y la publicidad que rodea a estos episodios también ayuda a que solamente se defiendan candidaturas apoyadas por currículos importantes ${ }^{63}$.

En Chile, la jurisprudencia del Tribunal Constitucional parece rechazar la posibilidad de establecer garantías de procedimiento, que permitan ejercer cierto control en las decisiones de selección de los jueces. El Tribunal Constitucional ha declarado la inconstitucionalidad del deber de motivación, señalando al efecto que la frase "mediante resolución fundada”, afectaba la potestad propositiva de la Corte Suprema ${ }^{64}$. Además, ha establecido la imposibilidad de hacer públicos los puntajes obtenidos en un concurso, tanto de la solicitante como de los demás postulantes en los procesos de selección de funcionarios $^{65}$. Como veremos más adelante, mientras que la Corte Suprema ha emitido una Resolución para reducir los ámbitos de discrecionalidad en el proceso de selección, la decisión del Ejecutivo se realiza por medio de un análisis adicional de los antecedentes enviados, independiente del orden de los postulantes de la terna. Dichos criterios no han sido formalizados, por lo que no hay claridad en su determinación ${ }^{66}$.

\section{El ingreso de los jueces en Chile}

Para la selección de los ministros de la Corte Suprema, la Corte Suprema propone al Gobierno cinco candidatos ("quina”) para cada cargo de ministro de Corte Suprema. De los 21 ministros de la Corte Suprema 16 deben haber ocupado cargos en el Poder Judicial al momento de ser seleccionados y 5 deben ser externos, personas con título de abogado que desarrollan su profesión fuera del Poder Judicial. Respecto de los candidatos

\footnotetext{
${ }^{60}$ BAG 12de septiembre de 2006 - Exp. 9 AZR 807/05, párr. 37

${ }^{61}$ Murillo, 2018a, p. 73; Lousada, 2015, p. 119.

${ }^{62}$ STS de 27.11.2007 REC. 407/2006; S. 3. ${ }^{\text {. }}$ Ver también, STS 3449/2008 de 12/06/2008.

63 Murillo, 2018a, p. 73 y Murillo, 2018b, p. 363.

64 TC Rol No 2180 de 17 de mayo de 2012.

${ }^{65}$ Sentencia N ${ }^{\circ}$ Rol 2290 de Tribunal Constitucional, 6 de agosto de 2013.

${ }^{66}$ SALDÍvAR, 2014, p. 41
} 
externos $^{67}$ solo se establecen ciertos requisitos mínimos, por lo que la decisión de la Corte Suprema había sido, hasta ahora, esencialmente discrecional ${ }^{68}$.

Para la selección de los candidatos internos la Constitución reserva un cupo de la lista de candidatos (la quina) creada por la Corte Suprema para el ministro más antiguo de la Corte de Apelaciones que figure en lista de méritos (art. 78 inciso 5 de la Constitución y 283 del COT). Para la selección de los restantes candidatos es relevante, en primer lugar, las calificaciones anuales que han recibido. En la práctica este criterio resulta insuficiente, debido a que la gran mayoría de los postulantes pertenecen a la misma lista. El segundo criterio es el de la categoría de los cargos de los postulantes, quienes generalmente serán ministros de Cortes de Apelaciones. Debido a que generalmente se presenta un superávit de candidatos, queda a la Corte Suprema un ámbito de discrecionalidad para determinar "otros antecedentes" que serán determinantes de la selección ${ }^{69}$.

Para reducir los ámbitos de discrecionalidad mencionados, la Corte Suprema ha emitido una Resolución que establece ciertas garantías, entre las que destaca la previsión de procedimientos de selección anónimos, mediante concursos "ciegos", conforme con criterios que impidan conocer la identidad de los participantes. Además, la autoridad encargada de conducir el concurso no será la que debe confeccionar la quina, terna, hacer la propuesta unipersonal o decidirla ${ }^{70}$.

Tanto para los candidatos internos como externos, el Presidente de la República, con asesoría del ministro de Justicia, tiene una potestad discrecional para seleccionar al candidato de la quina que propone al Senado. Finalmente, el Senado tiene la potestad de aprobar o rechazar el candidato del gobierno ${ }^{71}$. El quórum de dos tercios del Senado conduce al llamado cuoteo político, que se refiere al acuerdo implícito de los dos principales bloques políticos, que van alternando en la aprobación de los candidatos de su preferencia $^{72}$.

Un análisis crítico del sistema de selección de los ministros de la Corte Suprema debe tener por finalidad determinar si el margen de discrecionalidad que corresponde a la Corte Suprema, al Presidente de la República y al Senado, es conforme al principio de independencia de los jueces. Para ello podemos utilizar el criterio de idoneidad, es

${ }^{67}$ Véase también, VARgas, 2014, p. 151. Respecto de este tipo de cuotas, el Tribunal Supremo español ha señalado que lo buscado por el legislador en una y otra clase de turnos es que coincidan en este órgano jurisdiccional diferentes trayectorias téoricas y prácticas, para favorecer así el pluralismo de visiones jurídicas que se juzga conveniente en el Tribunal Supremo, también parece que deberán ser distintos los criterios de calificación de los candidatos que acudan por esas diferenciadas vías de acceso (STS de 27.11.2007 REC. 407/2006; S. 3. ${ }^{\mathrm{a}}$ ).

${ }^{68}$ MaCClure, 2019, p. 43.

${ }^{69}$ MacClure, 2019, pp. 42-43.

${ }^{70}$ Resolución del Pleno de la Corte Suprema de 7 de junio de 2019.

${ }^{71}$ Antes de la reforma de 1997, los ministros de corte y jueces eran nombrados por el Presidente de la República, quien debía elegir de entre una quina o terna propuesta por la Corte Suprema o la Corte de Apelaciones respectiva. Correa, 2005, p. 122. Crítico del poder de veto de un grupo minoritario, VARGAS, 2014, pp, 154 y sig.

${ }^{72}$ MacClure, 2019, p. 58. 
decir, si el método utilizado es suficiente garantía que las personas seleccionadas sean personas íntegras e idóneas y tengan la formación o las calificaciones jurídicas apropiadas. Además, es aplicable como parámetro del análisis el criterio de independencia política, en el sentido de si el sistema de nombramiento recompensa los contactos políticos ${ }^{73}$ y no el mérito, al punto que pueda generar el riesgo de comportarse de tal modo que obtenga el apoyo de la autoridad encargada de tal decisión, o de que su comportamiento se perciba de este modo por los justiciables ${ }^{74}$. Finalmente, el principio de mérito y el derecho de igualdad de acceso se exigirían solo si resulta seleccionado el aspirante más calificado ${ }^{75}$.

Respecto del principio de idoneidad para el ejercicio de las tareas de los ministros de la Corte Suprema, el procedimiento de elaboración de las listas de candidatos que forman parte de la carrera judicial se basa en la antigüedad de los ministros de Corte de Apelaciones, así como en las calificaciones anuales. El ámbito de discrecionalidad que deriva del superávit de candidatos, reducido por los procedimientos de selección anónimos, no impide que los preseleccionados ostenten la capacidad requerida para el cargo $^{76}$. El principio de idoneidad tampoco resulta incumplido por la mayor discrecionalidad de la Corte Suprema en la selección de los candidatos externos, en la medida en que se establecen garantías de objetividad en el proceso.

Los amplios márgenes de discrecionalidad que corresponden al Presidente de la República y al Senado tampoco afectarían el principio de idoneidad, debido a que el sistema de ternas garantiza que los candidatos ostentan calificaciones suficientes. Sin embargo, la intervención de los órganos políticos puede producir cierta distorsión en el resultado final. No se garantiza que el candidato seleccionado tenga mayores méritos que sus competidores. Si bien la incorporación de la participación del Senado disminuye el rol predominante del Ejecutivo, sin embargo con ello no se reduce el riesgo de que la decisión obedezca a motivos políticos. Desde el punto de vista del derecho subjetivo del aspirante al cargo de ministro de la Corte Suprema, el ámbito de discrecionalidad del Presidente de la República y del Senado resulta injustificado.

El criterio de independencia política, en el sentido de si el sistema de nombramiento recompensa los contactos políticos y no el mérito, o si puede ser percibido de este modo por los justiciables es también infringido por el ámbito de discrecionalidad política del Presidente de la República y del Senado. La mencionada distorsión concede un valor decisivo a la influencia política, que resulta extraño a la función judicial.

En todo caso, debemos advertir que la deficiencia anotada no constituye un vicio insuperable del sistema, sino un déficit que puede ser objeto de correcciones, por medio de la antes mencionada interpretación conforme, con garantías de procedimiento, que reduzcan la discrecionalidad política, en favor de una mayor transparencia y objetividad.

\footnotetext{
73 Carrillo, 1999.

${ }^{74}$ CIDH, 2013, párr. 88.

${ }^{75}$ VG Karlsruhe, Beschluss vom 17.01.2013-1 K 2614/12.

76 También en este sentido, VARGAS, 2014, p. 148.
} 
El esquema establecido para la designación de los ministros de la Corte Suprema es, en líneas generales, el mismo procedimiento que se encuentra establecido para el sistema de selección de los ministros de Corte de Apelaciones ${ }^{77}$; para la designación de los jueces y secretarios abogados de los Tribunales Tributarios y Aduaneros ${ }^{78}$; de los Tribunales Ambientales ${ }^{79}$ y para la la selección de los candidatos al cargo de relator de la Corte Suprema ${ }^{80}$, por lo que les son aplicables similares consideraciones que en el caso de la designación de los ministros de la Corte Suprema.

\section{Conclusiones}

La intervención decisiva de un órgano con discrecionalidad política constituye una distorsión extraña a la naturaleza de las funciones de los jueces. Si bien el procedimiento de elaboración de la terna garantiza la idoneidad de las personas seleccionadas, sin embargo, en el resultado final no se garantiza que el candidato seleccionado tenga mayores méritos que sus competidores, lo que resulta injustificado desde el punto de vista del derecho subjetivo del aspirante, así como en cuanto al riesgo de comportarse de tal modo que obtenga el apoyo de la autoridad encargada de tal decisión, o de que su comportamiento se perciba de este modo por los justiciables. Sin embargo, aun cuando sea recomendable la configuración de órganos independientes, que garanticen cierta distancia del centro del poder político, estimamos que es posible lograr una interpretación conforme con el principio de independencia judicial, mediante garantías de procedimiento, tal como ha sido propuesto en el derecho internacional y en la doctrina especializada.

La tesis de la dicotomía o de la separación puede ser ilustrada con el siguiente ejemplo. Con ocasión de la "Primera Gran Protesta Nacional" convocada en mayo de 1983, el gobierno logró la aplicación de los delitos contenidos en la Ley de Seguridad del Estado, pero el Tribunal de Apelaciones y la Corte Suprema decidieron que se trataba de una simple disidencia social o manifestaciones de opiniones ${ }^{81}$. En $2011 \mathrm{el}$ entonces ministro de Justicia criticó la actitud "ultragarantista” de algunos jueces con

77 MacClure, 2019, pp. 10; 28, 33; Mesa interinstitucional, 2019, p. 12.

${ }^{78}$ El Tribunal Constitucional consideró que si bien no es objetable la participación del Consejo de Alta Dirección Pública, sin embargo, las Cortes de Apelaciones no deberían tener limitaciones en la posibilidad de objetar la lista confeccionada por aquél de acuerdo con un perfil profesional de los cargos. TC Rol No 1243 de fecha 30-12-2008, 16². Crítico de esta decisión, Bordalí, 2009c, p. 261; Matus, 2013, p. 207.

${ }^{79}$ BoDin, 2013, p. 301 considera que se trata de una modalidad compleja y engorrosa, con intervención de los tres poderes del Estado, dejando sometida la designación de jueces especializados, de primera instancia, a acuerdos políticos, lo que afecta la independencia del tribunal.

${ }^{80}$ Zapata, 2008, p. 256. El Código Orgánico de Tribunales ofrece a la Corte Suprema un mayor control, lo cual deriva, por una parte, de la facultad de omitir la terna y someter al Presidente de la República una propuesta uninominal, y adicionalmente, del carácter difuso del criterio de evaluación que la Corte Suprema debe utilizar para seleccionar candidatos, lo cual reduce el ámbito de discrecionalidad del Presidente de la República. MacClure, 2019, p. 29.

${ }^{81}$ Zapata Larraín, P., 1986, p. 389. 
los detenidos por desórdenes públicos y anunció que a la hora de determinar los ascensos en las Cortes se tomaría en cuenta el historial de fallo de los jueces ${ }^{82}$. Recientemente, hemos visto la aplicación generalizada de la Ley de Seguridad del Estado y su importante efecto disuasivo en materia de protestas.

De esta forma, observamos que la dicotomía o absoluta incompatibilidad entre funciones de gobierno y jurisdiccionales interactúa dentro de un sistema de protección de la libertad individual junto con otros principios. Entre ellos, la garantía de reserva legal, según esta, toca al legislador, y solo a él, disponer la regulación del ejercicio de los derechos fundamentales. Esta garantía quedaría sin aplicación si, en la interpretación de la ley e incluso en ejercicio de algún margen de evaluación, el juez permitiera la influencia de los intereses de la contingente política del gobierno, en lugar de acudir de forma independiente a los valores de la Constitución.

A partir de la finalidad del principio de separación de poderes, de asegurar la protección de la esfera del individuo, podemos formular una regla de proporcionalidad: a mayor afectación de los derechos fundamentales del individuo por la aplicación de la ley, mayor separación o distancia, especialmente, respecto de los órganos del poder político. El mayor grado de independencia corresponde por ello a la jurisdicción civil, en la que -como advertía Savigny- se limita la libertad del deudor y a la jurisdicción penal, en virtud de ello se produce la mayor afectación de derechos del presunto delincuente. Se trata de un esquema orgánico que pretende impedir que la afectación de los intereses del individuo se realice por motivos distintos de los indicados de forma clara y determinada en la ley, mediante la separación entre la protección del contingente de interés general a cargo de los órganos del poder político y la intervención en la esfera individual, a cargo de la administración y los jueces.

\section{BIBLIOGRAFÍA}

Alcalá-Zamora y Castillo, Niceto, 1992: Notas relativas al concepto de jurisdicción, en Estudios de teoría general e historia del proceso (1945-1972) (Universidad Nacional Autónoma de México México), Tomo I: Números 1-11.

Atria, F., 2007: La improbabilidad de la jurisdicción, en Atria, Fernando y Couso, Javier (editores), La judicatura como organización (Santiago de Chile, Expansiva - Instituto de Estudios Judiciales) pp. 33-56. Disponible en: http://biblioteca.cejamericas.org/bitstream/ handle/2015/2475/lajudicaturacomoorganizacion.pdf? sequence $=1 \&$ isAllowed $=y$. Fecha de consulta: 22 de octubre de 2019.

Bodin, M. C. P., 2013: Los Tribunales Ambientales: se completa la reforma a la institucionalidad ambiental. Anuario de Derecho Público, (1), 297-315.

Bordalí Salamanca, A., 2009b: El derecho fundamental a un tribunal independiente e imparcial en el ordenamiento jurídico chileno. Revista de Derecho (Valparaíso), (33), 263-302. Disponible en: http://dx.doi.org/10.4067/S0718-68512009000200007. Fecha de consulta: 23 de octubre de 2019.

${ }^{82}$ Soto, 21.10.2011; Porras, 24.10.2011. 
Bordalí Salamanca, Andrés, 2007: Análisis crítico de la función e independencia judicial en el Derecho chileno, en Couso, Jaime - Atria, Fernando (editores), La judicatura como organización, Santiago: Instituto de Estudios Judiciales

Bordalí Salamanca, Andrés, 2008: La doctrina de la separación de poderes y el poder judicial chileno. Revista de Derecho (Valparaíso), (30), 185-219. Disponible en: https://dx.doi. org/10.4067/S0718-68512008000100004. Fecha de consulta: 23 de octubre de 2019.

Bordalí Salamanca, Andrés, 2009a: Organización judicial en el derecho chileno: un poder fragmentado. Revista Chilena de Derecho, 36(2), 215-244. Disponible en: https://scielo.conicyt. cl/pdf/rchilder/v36n2/art02.pdf. Fecha de consulta: 23 de octubre de 2019.

Bordalí Salamanca, Andrés, 2009c: ¿Independencia judicial? Depende (Sentencia del Tribunal Constitucional sobre los Tribunales Tributarios y Aduaneros). Revista de Derecho (Valdivia), 22(1), 237-264. https://dx.doi.org/10.4067/S0718-09502009000100011

Bordalí Salamanca, Andrés, 2013: La independencia de los jueces en la aplicación de la ley dentro de la organización judicial chilena. Revista Chilena de Derecho, 40(2), 609-634. Disponible en: https://dx.doi.org/10.4067/S0718-34372013000200010. Fecha de consulta: 12 de octubre de 2019.

Brewer-Carías, Allan R., 2005: La cuestión de legitimidad: ¿cómo escoger los jueces de las cortes supremas? Ponencia para el simposio sobre The Future of the European Judicial System. The Constitutional Role of European Courts,. 6th International European Constitutional Law Network- Colloquium/International Association of Conmstitutional Law-Round Table, 2-4 November 2005, Berlin, Gemany. https:// allanbrewercarias.com/wp-content/uploads/2015/11/64.-I-4-934.-La-cuesti\%C3\%B3n-dela-legitimidad-en-la-designaci\%C3\% B3n-de-los-jueces-de-la-Corte-Suprema.-Berlin.pdf p

Carrillo Flórez, F., 1999: Los retos de la reforma de la justicia en América Latina, en Fuentes (Coord.). Reforma judicial en América Latina: una tarea inconclusa. Corporacion Excelencia En La Justicia. Organización de Estados Americanos (OAS). http://www.oas.org/juridico/ spanish/adjusti2.htm

Català i Bas, A., y Ortiz Torricos, M., 2017: La comunicación horizontal y vertical en los sistemas americano y europeo de protección de derechos humanos a propósito del derecho al juez natural. Hacia un derecho global de los derechos humanos. Estudios de Deusto, 65(1), 73-121. doi:http://dx.doi.org/10.18543/ed-65(1)-2017pp73-121 p. 86

Comisión Interamericana de Derechos Humanos (CIDH), 2013: "Garantías para la independencia de las y los operadores de justicia. Hacia el fortalecimiento del acceso a la justicia y el Estado de derecho en las américas". https://www.oas.org/es/cidh/defensores/docs/pdf/ Operadores-de-Justicia-2013.pdf

Comité de Derechos Humanos Informe A/50/40 de 3 de octubre de 1995, http://docstore.ohchr. org/SelfServices/FilesHandler.ashx?enc =dtYoAzPhJ4NMy4Lu1TOebEYW2RK0bbpVx\% 2B6t9zQ8e7ocgLABpjDN\%2FkqksL3Zkn\%2F5XxXEEFEkUevZ0tIE9UcnarbuN6zA4u 0n6C4Yg7G4ICEMhlteFpQZ7lohYPNDoFtFjOyr4R5ZAB0bHvtdWm5yCA\%3D\%3D

Comité de Derechos Humanos, 2014: Observación General Núm. 35 sobre la libertad y seguridad personales. Disponible en: https://www.refworld.org/cgi-bin/texis/vtx/rwmain/opendocpdf. pdf? reldoc $=y \&$ docid $=553 \mathrm{e} 0 \mathrm{fb} 84$. Fecha de consulta: 23 de octubre de 2019 .

Consejo Consultivo de Jueces Europeos (CCJE), 2001, Informe N. ${ }^{\circ} 1$, sobre las normas relativas a la independencia y a la inamovilidad de los jueces. http://www.poderjudicial.es/stfls/ CGPJ/RELACIONES\%20INTERNACIONALES/COMISI\%C3\%93N\%20EUROPEA\%20 PARA $\% 20$ LA $\% 20$ EFICACIA $\% 20$ DE $\% 20$ LA $\% 20 J U S T I C I A / I N F O R M E S \% 20 C C J E /$ FICHERO/20011123\%20InformeCCJE(2001)OP1S.pdf 
Consejo de Europa. Comité de Ministros. Recomendación No. R (94) 12, sobre la independencia, eficiencia y rol de los jueces. Adoptada por el Comité de Ministros el 13 de octubre de 1994 en la 51ª reunión de Ministros. https://sid.usal.es/idocs/F3/LYN10470/3-10470.pdf Correa, R., 2005: El gobierno judicial ante la constitución. Revista de Estudios de la Justicia, (6), 117-126. http://web.derecho.uchile.cl/cej/recej/RECEJ\%206/EL\%20GOBIERNO\%20 JUDICIAL\%20ANTE\% 20LA\%20CONSTITUCION.pdf

DAMAŠKA, Mirjan R., 2000: Las caras de la justicia y el poder del estado: análisis comparado del proceso legal. Editorial Jurídica de Chile.

Dazarola Leichtle, Gabriela, 2018: Nombramiento magistrados tribunales superiores de justicia. Experiencia Extranjera. Biblioteca del Congreso Nacional de Chile. Asesoría Técnica Parlamentaria. https://www.bcn.cl/obtienearchivo?id=repositorio/10221/27333/1/ BCN_GRID_Nombramiento_Jueces_Tribunales_Superiores_experiencia_ext_def.pdf p. 7

Delaveau Swett, Rodrigo et al, 2017: Estudio modelo orgánico para la nueva justicia. Informe final Pontificia Universidad Católica de Chile. http://decs.pjud.cl/documentos/descargas/ Estudio_Modelo_Orga_nico_Final.pdf p. 21

Durango Álvarez, G. A., 2007: Aproximaciones conceptuales a la democracia constitucional y a los derechos fundamentales en la Teoría de L. Ferrajoli. Opinión Jurídica, 6(12). Disponible en: http://www.scielo.org.co/pdf/ojum/v6n12/v6n12a10.pdf. Fecha de consulta: 07 de octubre de 2019.

Eser, A., 1996: Rechtsgut und Opfer: zur Überhöhung des einen auf Kosten des anderen. Sonderdrucke aus der Albert-Ludwigs-Universität Freiburg. Originalbeitrag erschienen in: Ulrich Immenga (Hrsg.): Festschrift für Ernst-Joachim Mestmäcker. Baden-Baden: Nomos Verlagsges., 1996, S. 1005-1024. Nomos Verlagsgesellschaft. Baden Baden. https://freidok. uni-freiburg.de/data/3386

Ferrajoli et al., 2001: Los fundamentos de los derechos fundamentales. Madrid: Trotta.

Ferrajoli, L., 1987: El juez en una sociedad democrática. Disponible en: http://biblioteca.cejamericas. org/bitstream/handle/2015/1887/eljuezenunasociedemocratica.pdf? sequence=1\&isAllowed $=y$. Fecha de consulta: 23 de octubre de 2019.

Ferrajoli, L., 2005: El papel de la función judicial en el Estado de Derecho. Jurisdicción y argumentación en el Estado constitucional de derecho en Miguel Carbonell, J. et all (Coord) Jurisdicción y argumentación en el estado constitucional de derecho. Universidad Nacional Autónoma de México, Instituto de Investigaciones Jurídicas.

Ferrajoli, L., 2013: Principia iuris: teoría del derecho y de la democracia: 1. Teoría del derecho. Editorial Trotta, SA. Cit. Ferrajoli (2013a).

Ferrajoli, L., 2013: Principia iuris: teoría del derecho y de la democracia: 2. Teoría de la democracia. Editorial Trotta, SA. Cit. Ferrajoli (2013b).

Ferrajoli, Luigi, 2006: Garantismo. Una discusión sobre derecho y democracia, Madrid: Trotta p. 97.

Fuentes, C. G., 2016: Principios internacionales que consagran el derecho humano de acceso a una justicia independiente. Análisis del tema en Argentina. Revista de Estudios de la Justicia, (25), 199-246. https://www.refworld.org/cgi-bin/texis/vtx/rwmain/opendocpdf. pdf? reldoc $=y \&$ docid $=4 a 7838272$ p. 211

Fuentes, Claudia, 2011: Montesquieu: Teoría de la distribución social del poder. Revista de Ciencia Política [en linea], 31 (Sin mes). Disponible en: http://www.redalyc.org/articulo. oa? id=32419207003. Fecha de consulta: 22 de febrero de 2018 .

Fuenzalida \& Valderrama, 2017: La potestad consultiva del Tribunal de Defensa de la Libre Competencia:¿ jurisdiccional o administrativa? Revista Derecho Administrativo Económico, 
(13), 181-198. Disponible en: http://redae.uc.cl/index.php/redae/article/viewFile/199/192. Fecha de consulta: 23 de octubre de 2019.

Galindo Ayuda, F, 1990: Jueces y Democracia: Criterios para una actividad judicial democrática. Anuario de filosofía del derecho, (7), 147-168. Disponible en: https://dialnet.unirioja.es/ descarga/articulo/142179.pdf. Fecha de consulta: 3 de octubre de 2019.

García, C. M. R., y Torres, M. G. M., 2011: Las garantías jurisdiccionales de los impartidores de justicia. Nuevo derecho, 7(9), 59-72. https://dialnet.unirioja.es/descarga/articulo/5549124. pdf p. 60 .

Gaviria Mira, Julián., 2019: Constitucionalismo garantista: Democracia y soberanía popular sin pueblo. Revista Chilena de Derecho, 46(1), 155-175. Disponible en: https://dx.doi.org/10.4067/ S0718-34372019000100155. Fecha de consulta: 3 de octubre de 2019.

GonzÁlez Álvarez, Roberto, 2014: El nuevo paradigma de la garantía de la jurisdicción. Ars Boni et Aequi, 10(1), 119-150. Disponible en: https://dialnet.unirioja.es/descarga/articulo/5853784.pdf. Fecha de consulta: 23 de octubre de 2019.

Gordillo, Agustín, 2017: Tratado de derecho administrativo y obras selectas: Parte general, Buenos Aires: Fundación de Derecho Administrativo. Disponible en: https://www.gordillo.com/ pdf_tomo1/tomo1.pdf. Fecha de consulta: 23 de octubre de 2019.

HarbotTle Quirós, F., 2019: El poder de decisión del juez en un Estado de derecho: aportes de Max Weber al debate actual. Lex - Revista de la Facultad de Derecho y Ciencias Políticas, 16(22), 17-36. Disponible en: doi:http://dx.doi.org/10.21503/lex.v16i22.1646. Fecha de consulta: 23 de octubre de 2019.

InTERnATIONAL Bar Association, 2010: Los derechos humanos en la administración de justicia: un manual de derechos humanos para jueces, fiscales y abogados. https://www.ibanet.org/ Document/Default.aspx?DocumentUid=A01791F1-D01B-4F73-9A64-293F6B7B5736 p. 134.

JellineK, G., und Jellinek, W., 1921: Allgemeine Staatslehre. 3. Auf. Springer-Verlag Berlin Heidelberg GmbH.

Loewenstein, Karl, 1959: Verfassungsrecht und Verfassungspraxis der Vereinigten Staaten. Springer-Verlag Berlin Heidelberg GmbH.

Loewenstein, Karl, 1967: Staatsrecht und Staatspraxis von Grossbritannien. Band II. Justiz o Verwaltung, Bürgerrechte. Springer-Verlag Berlin Heidelberg GmbH.

Lopera Mesa, G. P., 2001: La problemática legitimidad de la justicia constitucional. Anuario iberoamericano de justicia constitucional, (5), 227-256. Disponible en: https://dialnet.unirioja. es/descarga/articulo/1976017.pdf. Fecha de consulta: 07 de octubre de 2019.

López Guerra, L., 1997: La legitimidad democrática del juez. Cuadernos de Derecho Público. Disponible en: https://dialnet.unirioja.es/descarga/articulo/197115.pdf.

López Guerra, L., 2018: El papel del juez en una sociedad democrática. Revista Estudios Jurídicos. Segunda Época, (18). Disponible en: https://revistaselectronicas.ujaen.es/index.php/rej/article/ view/4494/3687. Fecha de consulta: 23 de octubre de 2019.

Lousada Arochena, \& Ron Latas, 2015: La independencia judicial. Dykinson. p. 119.

Lucas Garín, Andrea, 2009: "Nuevas dimensiones del principio de división de poderes en un mundo globalizado". Año 7, N² 2, 2009, pp. 241-253, ISSN 0718-0195. Centro de Estudios Constitucionales de Chile, Universidad de Talca. Disponible en: https://scielo.conicyt.cl/ pdf/estconst/v7n2/art09.pdf. Fecha de consulta: 23 de octubre de 2019.

MacClure Brintrup, Lucas, 2018: “Reformas a la Justicia 2006-2017”, Debates de Política Pública, No 27, enero 2018, 123-124: https:/www.cepchile.cl/cep/site/docs/20180129/20180129102359/ dpp_027_enero2018_lmclure.pdf p. 4.

MacClure Brintrup, Lucas, 2019: Nombramientos de ministros de las cortes de apelaciones y de la Corte Suprema: Síntesis y sistematización de su regulación. Debates de Política 
Pública No 32 / mayo 2019. Centro de Estudios Públicos. https://www.cepchile.cl/cep/site/ docs/20190523/20190523170012/dpp_032_lmacclure_mayo2019.pdf p. 43.

Mateos Martinez, J., 2019: ¿ Cómo garantizar que el juez sea digno de su poder? Reflexiones sobre la independencia del poder judicial con base en el sistema político español. Ars Boni et Aequi, 14(2). http://www.arsboni.ubo.cl/index.php/arsbonietaequi/article/viewFile/318/308 p. 146

Matus F, Marcelo, 2013: Aspectos orgánicos de la jurisdicción tributaria y aduanera: Comentario crítico a la Ley $n^{\circ} 20.322$ con motivo de su entrada en vigencia en todo el territorio nacional. Ius et Praxis, 19(1), 195-222. https://dx.doi.org/10.4067/S0718-00122013000100006

Melgarejo, R. C., 2019: Cambio de modelo institucional e independencia judicial. Derecho y Cambio Social, (58), 593-624. Disponible en: https://dialnet.unirioja.es/descarga/articulo/7075620.pdf. Fecha de consulta: 03 de octubre de 2019.

Mesa interinstitucional sobre nombramientos de jueces, 2019: Informe final: conclusiones y recomendaciones de la mesa interinstitucional sobre nombramiento de jueces. http://www. magistrados.cl/wp- content/uploads/2019/01/Informe-final-mesa.pdf p. 8

Moraga Klenner, C., 2011: ¿Existen en Chile procedimientos administrativos que presentan, también, una naturaleza jurisdiccional?. Derecho PUCP, 2(67), 231-251. Disponible en: https:// dialnet.unirioja.es/descarga/articulo/5085088.pdf. Fecha de consulta: 23 de octubre de 2019.

Moreno Vida, N. M., 2018: El derecho a un proceso equitativo en el convenio europeo de derechos humanos. Temas laborales: Revista andaluza de trabajo y bienestar social, (145), 87-119. https://www.iustel.com/v2/revistas/detalle_revista.asp?id_noticia $=413596$

Muller Bitencourt, Caroline \& Clovis Gorczevski, C., 2016: La función y la legitimidad del poder judicial en el constitucionalismo democrático brasileño: ¿ un activismo necesario?. Estudios constitucionales, 14(2), 207-230. Disponible en: https://scielo.conicyt.cl/pdf/ estconst/v14n2/art07.pdf. Fecha de consulta: 22 de febrero de 2018

Murillo De La Cueva p. L., 2018a: La independencia y el gobierno de los jueces: un debate constitucional. Madrid. Editorial Reus p. 73

Murillo de la Cueva, P., 2018b: La independencia y el gobierno de los jueces. Un debate constitucional. Teoría y Realidad Constitucional, O(40), 351-368. doi:https://doi.org/10.5944/ trc.40.2017.20911

Naciones Unidas Informe del Comité de Derechos Humanos Volumen I Asamblea General Documentos Oficiales Quincuagésimo segundo período de sesiones Suplemento No. 40 (A/52/40). http://docstore.ohchr.org/SelfServices/FilesHandler.ashx?enc=dtYoAzPhJ4NMy4Lu1TOebM0H3O6soCEvpX\%2F8RwmnAPG4P6RHwvjU6MmZ02IWU6dl7oznic ASA7kTCvlL55HSR1QK7TD8P10XA7pbBMZW6PyKzsn0\%2F7zUsPRKjvGqQbjigb ER\%2FvL97iMZAs4oNRwV7w\%3D\%3D p. 224.

Nieto, A., 2007: La administración de justicia y el Poder Judicial. Revista de administración pública, (174), 31-47. Disponible en: https://dialnet.unirioja.es/descarga/articulo/6800394. pdf. Fecha de consulta: 23 de octubre de 2019.

Nieva Fenoll, Jordi, 2017: Seis conceptos en busca de un objetivo: jurisdicción, acción, proceso, derechos, pena y delito. Política criminal, 12(23), 103-123. Disponible en: https://dx.doi. org/10.4067/S0718-33992017000100004. Fecha de consulta: 23 de octubre de 2019.

Pérez-Cruz Martín, Agustín-Jesús, 2015: Constitución y poder judicial, Atelier. Disponible en: http://facultad.pucp.edu.pe/derecho/wp-content/uploads/2015/03/Constituci\%C3\%B3ny-Poder-Judicial..pdf]

Popkin, M., 2002: Esfuerzos para aumentar la independencia e imparcialidad judicial en América Latina. Revista Sistemas Judiciales, 4, 47-60. Disponible en: HTTPs://sistemasjudiCiales. 
ORG/WP-CONTENT/UPLOADS/2OI 8/O8/TEMACENTRAL_MPOPKIN.PDF. Fecha de consulta: 22 de febrero de 2018

Porras, 24.10.2011: Milton Juica: "La evaluación de los jueces le corresponde exclusivamente al Poder Judicial”. https://radio.uchile.cl/2011/10/24/milton-juica-\%E2\%80\%9Cla-evaluacionde-los-jueces-le-corresponde-exclusivamente-al-poder-judicial\%E2\%80\%9D/

Posner, Richard A., 2011: Cómo deciden los jueces. Traducción de Victoria Roca Pérez. Madrid. Marcial Pons.

Principios Básicos de las Naciones Unidas Relativos a la Independencia de la Judicatura adoptados por el Séptimo Congreso de las Naciones Unidas sobre Prevención del Delito y Tratamiento del Delincuente, celebrado en Milán, Italia, del 26 de agosto al 6 de septiembre de 1985, y confirmados por la Asamblea General en sus resoluciones 40/32 del 29 de noviembre de 1985 y 40/146 del 13 de diciembre de 1985. https://www.ohchr.org/sp/professionalinterest/ pages/independencejudiciary.aspx.

Quirós, F. V., 2018: Los fines de la justicia civil en el Estado constitucional de derecho. Revista de Estudios de la Justicia, (29), 73-120. p. 93. En cuanto a la situación en Latinoamérica, , p. 9

Ramos Ortells, Manuel, 1984: Aproximación al concepto de potestad jurisdiccional en la Constitución Española. Anuario de la Facultad de Derecho, (3), 415-458. Disponible en: https:// dialnet.unirioja.es/descarga/articulo/814914.pdf. Fecha de consulta: 22 de febrero de 2018

Relatora Especial sobre la cuestión de Defensores de la ONU. Folleto No. 29. Los Defensores de los Derechos Humanos: Protección del Derecho a Defender los derechos. Disponible en: https://www.ohchr.org/documents/publications/factsheet29sp.pdf. Fecha de consulta: 23 de octubre de 2019.

Resolución del Pleno de la Corte Suprema de 7 de junio de 2019 AD-626-2019. https:// www.pjud.cl/documents/2538811/0/resol + AD-626-2019+NOMBRAMIENTOS. pdf/1546b127-7e3b-4389-8f7d-d9efac02f64d

Rodríguez Collao, Luis, 2010) Bases para distinguir entre infracciones criminales y administrativas en Revista de Derecho de la Pontificia Universidad Católica de Valparaíso, 11.

SÁEz, F., 2005: La naturaleza de las reformas judiciales en América Latina: algunas consideraciones estratégicas, en Fuentes (Coord.). Reforma judicial en América Latina: una tarea inconclusa. Corporacion Excelencia En La Justicia. Organización de Estados Americanos (OAS). Disponible en: http://www. oas. org/Juridico/spanish/adjusti9. Htm. Fecha de consulta: 03 de octubre de 2019.

SALDívar Lobos, Georgina et al, 2014: Propuesta de un modelo de perfil y formación del juez civil en la nueva justicia procesal civil. Informe Final. Centro de Estudios y Asistencia Legislativa. Pontificia Universidad Católica de Valparaíso. http://biblioteca.digital.gob.cl/ bitstream/handle/123456789/643/Inf.\%20Final_Est.\%20modelo\%20de\%20perfil\%20y\%20 formaci\%C3\%B3n\%20juez\%20civil_CEAL\%20PUCV.pdf?sequence=1\&isAllowed=y, p. 41

SchnellenbaCH, H., 2018: Konkurrenzen im öffentlichen Dienst. CF Müller GmbH. p. 313.

SKAAR, E., 2003: Un análisis de las reformas judiciales de Argentina, Chile y Uruguay. América Latina Hoy, (34), 147-186. Disponible en: https://gredos.usal.es/bitstream/handle/10366/120606/ Un_analisis_de_las_reformas_judiciales_d.pdf;jsessionid=DFE09D41C83BEB1F295CB1 2EAE59BE67? sequence $=1$. Fecha de consulta: 23 de octubre de 2019.

Sото, 21.10.2011: Ministro de Justicia provoca controversia con declaraciones hacia jueces y molestia de Juica. https://www.biobiochile.cl/noticias/2011/10/21/ministro-de-justiciaprovoca-controversia-con-declaraciones-hacia-presidente-de-la-corte-suprema.shtml

Uмвасн, D. C., und Dollinger, F. W., 2007: Zwischen Bestenauslese und Demokratieprinzip: die Besetzung der Landesrechnungshöfe unter Berücksichtigung der Bewerbung, Wahl und Ernennung der Mitglieder des Rechnungshofs Brandenburg. 
USAID/IFES, 2002: Pautas para promover la independencia y la imparcialidad judicial, Introducción, www.cejamericas.org

VAN Hoecke, Mark, 2012: Tribunales constitucionales y democracia deliberativa. Revista de Derecho, $\mathrm{N}^{\circ}$ 28, 2012. pp. 9-25. Disponible en: https://www.cde.cl/wps/wcm/connect/1aed0070-ba88427a-9bfe-05378e20c272/rev+28+03+MARK+VAN+HOECKE.pdf? MOD=AJPERES. Fecha de consulta: 03 de octubre de 2019.

VArgas Viancos, Juan Enrique, 2018: Chile, en Gobierno Judicial Independencia y fortalecimiento del Poder Judicial en América Latina. Alberto M. Binder y Leonel González Postigo (Directores). Centro de Estudios de Justicia de las Américas, CEJA, Santiago de Chile.

VARgas Vivancos, J. E., 2014: Nombramientos y promociones judiciales: ¿es realmente la política el problema? Anuario de Derecho Público, (1), 140-162. http://derecho.udp.cl/wp-content/ uploads/2016/08/Anuario2014.pdf, p. 143.

Von SAVigny, F. K., 1879: Sistema del derecho romano actual (Tomo 4). Traducido del aleman por Guenoux. Madrid, F. Góngora y Compañía.

Wittreck, F., 2006: Die Verwaltung der Dritten Gewalt (Vol. 143). Mohr Siebeck. p. 421.

Zapata García, F., 2008: Sin temor ni esperanza. Condiciones estructurales de una eficiente juridificación de las espectativas normativas. Revista de Estudios de la Justicia, (10), 251-264. http://web.derecho.uchile.cl/cej/rej10/ZAPATA.pdf p. 256.

ZAPATA Larraín, P., 1986: El derecho a disentir ante la ley penal: análisis del artículo $6^{\circ}$ letra i de la ley 12.927 de Seguridad del Estado. Revista Chilena de Derecho. Vol. 13, No. 2 (mayo-agosto 1986), pp. 383-404. https://repositorio.uc.cl/bitstream/handle/11534/14420/000308038. pdf? sequence $=1$.

\section{Jurisprudencia}

BAG, 06.05.2014 - 9 AZR 724/12. http://juris.bundesarbeitsgericht.de/cgi-bin/rechtsprechung/ document. py? Gericht $=$ bag \&Art $=$ en\&nr $=17518$

BAG, 12.09.2006 - 9 AZR 807/05. https://openjur.de/u/171220.html

BAG, 12.10.2010 - 9 AZR 518/09. https://dejure.org/ext/123d71131f37537b6647f9c6ff64f1c7

BVERFG, 25.11.2011 - 2 BvR 2305/11. https://www.bundesverfassungsgericht.de/SharedDocs/ Entscheidungen/DE/2011/11/rk20111125_2bvr230511.html

BVerfG, Beschluss der 1. Kammer des Zweiten Senats vom 25. November 2015 - 2 BvR 1461/15 -, Rn. (14), http://www.bverfg.de/e/rk20151125_2bvr146115.html

BVerfG, Beschluss des Zweiten Senats vom 16. Dezember 2015. - 2 BvR 1958/13 -, Rn. 31. http://www.bverfg.de/e/rs20151216_2bvr195813.html

BVerfG, Beschluss des Zweiten Senats vom 20. September 2016 - 2 BvR 2453/15 -, Rn. (17). Disponible en: http://www.bverfg.de/e/rs20160920_2bvr245315.html. Fecha de consulta: 23 de octubre de 2019.

BVERFG, Beschluss vom 24.09.2002 - 2 BvR 857/02. https://openjur.de/u/180890.html

BVERfGE 83, 60 - Ausländerwahlrecht II. http://www.servat.unibe.ch/dfr/bv083060.html. Fecha de consulta: 03 de octubre de 2019.

BVERwG 2 C 23.03, Urteil vom 28. Oktober 2004. https://www.bverwg.de/281004U2C23.03.0

BVERwG 2 VR 1.16, Beschluss vom 21. Dezember 2016, Abs. 21. https://www.bverwg. de/211216B2VR1.16.0

Corte Constitucional de Colombia C-1143/00. http://www.corteconstitucional.gov.co/ relatoria/2000/C-1143-00.htm

Corte Constitucional de Colombia. C-349/17. https://www.corteconstitucional.gov.co/ relatoria/2017/C-349-17.htm 
Corte Constitucional de Colombia. C-436/13. Disponible en: https://www.corteconstitucional. gov.co/relatoria/2013/C-436-13.htm. Fecha de consulta: 23 de octubre de 2019.

Corte Interamericana de Derechos Humanos Caso Caballero Delgado y Santana, Sentencia de 8 de diciembre de 1995. Serie C No. 22. Disponible en: http://www.corteidh.or.cr/docs/ casos/articulos/seriec_22_esp.pdf > consultado el 28/06/2016. Fecha de consulta: 22 de febrero de 2018.

Corte Interamericana de Derechos Humanos Caso Chocrón Chocrón VS. Venezuela Sentencia de 1 de julio de 2011 (Excepción Preliminar, Fondo, Reparaciones y Costas). http://corteidh. or.cr/docs/casos/articulos/seriec_227_esp.pdf, párr. 97.

Conte Interamericana de Derechos Humanos Caso del Tribunal Constitucional Vs. Perú. Fondo, Reparaciones y Costas. Sentencia de 31 de enero de 2001. Serie C No. 71, párr. 75. http:// www.corteidh.or.cr/docs/casos/articulos/seriec_71_esp.pdf

Corte Interamericana de Derechos Humanos Caso Palamara Iribarne Vs. Chile. Fondo, Reparaciones y Costas. Sentencia de 22 de noviembre de 2005. Serie C No. 135. http://www.corteidh. or.cr/docs/casos/articulos/seriec_135_esp.pdf

Corte Interamericana de Derechos Humanos Caso Reverón Trujillo Vs. Venezuela. Excepción Preliminar, Fondo, Reparaciones y Costas. Sentencia de 30 de junio de 2009. Serie C No. 197. http://www.corteidh.or.cr/docs/casos/articulos/seriec_197_esp.pdf

Corte Suprema, Sala Cuarta (Mixta) Causa No 1482/2018 (Unificación de Jurisprudencia). Resolución No 6 de 3 de Abril de 2018. ID vLex: 707596289. Disponible en: http://cortesuprema-justicia.vlex.cl/vid/sanchez-ilustre-municipalidad-castro-707596289. Fecha de consulta: 23 de octubre de 2019.

OVG Schleswig-Holstein, 21.10.2019-2 MB 3/19. Disponible en: http://www.gesetzerechtsprechung.sh.juris.de/jportal/portal $/ \mathrm{t} / 203 \mathrm{~m} /$ page/bsshoprod.psml;jsessionid $=\mathrm{C} 7 \mathrm{D}$ DBE0C3F649416A2D2BE582B113E12.jp14? pid = Dokumentanzeige\&showdoccase $=1$ \&js_peid $=$ Trefferliste\&documentnumber $=1$ \&numberofresults $=1 \&$ fromdoctodoc $=$ yes \&d oc.id=MWRE190003572\%3Ajuris-r02\&doc. part $=$ L\&doc. price $=0.0 \&$ doc. hl $=1$. Fecha de consulta: 23 de octubre de 2019.

Sentencia del Tribunal Europeo de Derechos Humanos Caso Langborger contra Suecia de 22 de junio de 1989, párr. 116. http://hudoc.echr.coe.int/eng?i=001-164737

Sentencia Nº Rol 2290 de Tribunal Constitucional, 6 de Agosto de 2013. ID vLex: 453102406 http://jurisprudencia.vlex.cl/vid/-453102406

STC 108/1986, de 29 de julio. Disponible en: http://hj.tribunalconstitucional.es/es-ES/Resolucion/ Show/671. Fecha de consulta: 03 de octubre de 2019.

STEDH 10328/83 Caso Belilos c. Suiza de 29 de abril de 1988 http://hudoc.echr.coe.int/ eng? i=001-164749, párr. 64 .

STEDH 10328/83 Caso Belilos c. Suiza de 29 de abril de 1988 http://hudoc.echr.coe.int/ eng? $\mathrm{i}=001-164749$

STEDH 9273/81 Caso Ettl y otros de 23 de abril de 1987. http://hudoc.echr.coe.int/eng?i=001165059 , párr. 38.

STS 3449/2008 de 12/06/2008. http://www.poderjudicial.es/search/documento/TS/112548/ Empleo\%20publico/20080717

STS de 27.11.2007 REC. 407/2006; S. 3. . . https://www.iustel.com/diario_del_derecho/noticia. asp?ref_iustel $=1027400$

TC N ${ }^{\circ}$ Rol 2690 de 6 de Agosto de 2015. Disponible en: https://www.tribunalconstitucional. cl/ver2.php? id=3145. Fecha de consulta: 23 de octubre de 2019.

TC Rol No 3016-16 de 09 de mayo de 2016. Disponible en: https://www.tribunalconstitucional. cl/ver2.php?id=3251. Fecha de consulta: 03 de octubre de 2019. 
TC Rol N³329-17 de 23 de Agosto de 2018, 13. ID vLex: 737519481. Disponible en: http:// jurisprudencia.vlex.cl/vid/737519481. Fecha de consulta: 22 de febrero de 2018.

TC Rol N³729-17 de 28 de Agosto de 2017, 27. ID vLex: 692332513 http://jurisprudencia. vlex.cl/vid/692332513

TC Rol No 1243 de fecha 30-12-2008. Disponible en: https://www.tribunalconstitucional.cl/ ver2.php?id=1076. Fecha de consulta: 22 de febrero de 2018.

TC Rol No 1448-09 de 07 de septiembre de 2010. Disponible en: https://www.tribunalconstitucional.cl/ver2.php?id=1522. Fecha de consulta: 03 de octubre de 2019.

TC Rol No 1518-09 de 21 de octubre de 2009. Disponible en: https://www.tribunalconstitucional. $\mathrm{cl} /$ ver2.php?id=1587. Fecha de consulta: 03 de octubre de 2019.

TC Rol No 2180 de fecha 17 de Mayo de 2012, 27º. ID vLex: 371897638. Disponible en: http:// jurisprudencia.vlex.cl/vid/-371897638. Fecha de consulta: 23 de octubre de 2019.

TC Rol No 2381-12 de 20 de agosto de 2013. Disponible en: https://www.tribunalconstitucional. cl/ver2.php?id=2822. Fecha de consulta: 03 de octubre de 2019.

TC Rol No 2897-15 de 4 de Julio de 2017. https://www.tribunalconstitucional.cl/ver2.php? id=3447. Fecha de consulta: 03 de octubre de 2019.

TC Rol No 46-87, de fecha 21-12-1987. Disponible en: https://www.tribunalconstitucional.cl/ ver2.php?id=563. Fecha de consulta: 03 de octubre de 2019.

VG Karlsruhe, Beschluss vom 17.01.2013 - 1 K 2614/12. https://openjur.de/u/608517.html 
